\title{
Experimental Study on the Durability of Fly Ash-Based Filling Paste in Environments with Different Concentrations of Sulfates
}

\author{
Boqiang Cui, ${ }^{1}$ Yin Liu $\left(\mathbb{D},{ }^{1,2}\right.$ Hao Guo, ${ }^{1}$ Zhanxin Liu, ${ }^{1}$ and Yao Lu ${ }^{1}$ \\ ${ }^{1}$ State Key Laboratory of Mining Disaster Prevention and Control Co-founded by Shandong Province and the Ministry of Science \\ and Technology, Shandong University of Science and Technology, Qingdao 266590, China \\ ${ }^{2}$ Henan Key Laboratory for Green and Efficient Mining and Comprehensive Utilization of Mineral Resources, \\ Henan Polytechnic University, Jiaozuo 454000, China \\ Correspondence should be addressed to Yin Liu; liuyin-73@163.com
}

Received 18 January 2018; Revised 3 April 2018; Accepted 17 July 2018; Published 19 August 2018

Academic Editor: Estokova Adriana

Copyright ( $\odot 2018$ Boqiang Cui et al. This is an open access article distributed under the Creative Commons Attribution License, which permits unrestricted use, distribution, and reproduction in any medium, provided the original work is properly cited.

\begin{abstract}
In order to study the effects of different concentrations of sulfate on the strength of fly ash-based coal mine filling paste, using variable control, mechanical analysis, and other means, the changes in the uniaxial compressive strengths of filling paste blocks soaked in different concentrations of sodium sulfate solution for different durations are studied, and their stress-strain curves are discussed. The hydrated products of each block are analyzed at different stages by XRD, and the results indicate that different concentrations of sodium sulfate solution have different effects on the strength of the filling paste after soaking for different durations. A sodium sulfate solution with a concentration of $5 \%$ had an activator effect on the fly ash-based filling paste and enhanced the strength of the filling paste. A sodium sulfate solution with a concentration of $10 \%$ and $15 \%$ increased the early strength of the paste test block faster, but after $60 \mathrm{~d}$, the strength decreased. The stress-strain curves for these blocks show that the elastic moduli of the filling paste test blocks change irregularly, and it was found that with the increase in soaking time, the blocks soaked in the $10 \%$ and $15 \%$ sodium sulfate solutions developed fissures in the later stage that adversely affected the strength of the filling paste. The XRD results show that the filling paste test block hydration products are hydrated calcium silicate (C-S-H) based and that ettringite (AFt), beneficial to strength of the filling paste in proper quantities, appeared in the main product of the filling paste test blocks that were soaked in the sodium sulfate solution. With the increase in the concentration of the sodium sulfate solution, the AFt is generated in larger quantities, and gypsum crystals begin to appear, which is not conducive to the filling paste block strength.
\end{abstract}

\section{Introduction}

Coal mine paste filling technology is an important part of green coal mining: it not only plays a significant role in supporting the overlying strata, preventing or reducing surface subsidence of the coal mine [1-5], but also provides an effective solution the problem of "three under, one above" mining (mining under a building, under a railway, under a water body, or above confined water) [6,7]. As a result of its usefulness, paste filling technology has been widely applied and practiced in the field of mine filling. As a core component of filling technology, filling materials have always been the focus of research, with particular focus in recent years on how to both reduce the cost of filling and ensure the safety of mine production [8-11]. Paste filling materials consist of aggregates and cementitious materials. The use of fly ash in filling paste offers many potential benefits. Fly ash has the potential for cementitious activity, is cheap and easily sourced, and its use reduces the pollution of fly ash in the environment, thus more and more scientists have been interested in its potential applications. Much research has been conducted on the effects of fly ash content, particle size, activity, and conveyance performance on the performance of coal filling paste [12-17].

After entering the goaf, the filling paste is often in a complex mine environment. The coupling of different properties such as temperature, chemistry, and pressure has a certain influence on the long-term stability of the filling 
paste [18-21]. Most of the mine water contains sulfate, chlorine salt, and other substances; the filling paste is soaked in the mine water for a long time, and it can interact with these salts, thus causing the change of performance. Among them, the influence of sulfate on filling paste properties cannot be ignored $[22,23]$. Some studies have shown that a proper amount of sulfate can stimulate the activity of the fly ash in the filling paste, promoting early paste strength. Feng et al. [24] used the lime absorption method to explore the excitation effect of different activators on fly ash activity and concluded that the effect of sulfate excitation was superior to that of chlorine salt excitation, and the higher the sodium sulfate concentration, the more obvious the excitation effect. Guo et al. [25] investigated the microstructures of gypsum and fly ash adhesives by using X-ray diffraction, scanning electron microscopy, and pore structure analysis, and it is proved that desulfurization gypsum can effectively destroy $\mathrm{Si}-\mathrm{O}$ and $\mathrm{Al}-\mathrm{O}$ bonds in fly ash particles and produce AFt and other substances, so as to improve the compressive strength and tensile bond strength of fly ash-cemented material. He and Wei [26] studied the effect of sulfate on the performance of fly ash-cement adhesives with different fly ash contents using strength tests, and the results show that in a certain sulfate range, the greater the amount of activator is, the better the effect of fly ash will be. Ke et al. [27] theoretically analyzed the mechanisms of the effects of desulfurization gypsum on the activity of a cement-fly ash material; it is believed that the activation mechanism of sulfate to fly ash is mainly $\mathrm{SO}_{4}{ }^{2-}$ under the action of $\mathrm{Ca}^{2+}$ reacting with $\mathrm{AlO}_{2}{ }^{-}$on the surface of fly ash particles to generate AFt.

However, excessive sulfate can corrode the filling paste, which is unfavorable to the long-term stability of the hardened paste. Fall and Benzaazoua [28] analyzed the strength change trend of the filling paste in a sulfate environment by establishing mathematical models and proved that when the sulfate concentration is too high, the later strength of the filling paste will be adversely affected. Through strength tests and microanalysis, Pokharel and Fall [29] and Fall and Pokharel [30] explored the coupling effect of sulfate and temperature on the durability of the filling paste. Liu et al. [31] analyzed the corrosion and degradation mechanisms of filling materials in an acidic environment by means of intensity detection, scanning electron microscopy, and X-ray diffraction and studied the products generated by filling bodies subjected to a sulfate environment over time, indicating that excessive production of Aft and other substances is a key factor in reducing the strength of the filling paste. Sun et al. [32] studied the creep characteristics of the filling paste after sulfate attack by mechanical analysis and determined the one-dimensional and three-dimensional constitutive creep equations; the studies show that the accelerated creep of paste is filled in the later stage of sulfate attack, which affects the filling effect. Li and Fall [33] used thermogravimetric analysis and X-ray diffractometry to examine the compositional changes of the filling paste under sulfate attack and explored the influence mechanisms of sulfate on early filling paste performance.

Many studies have demonstrated that although an appropriate amount of sulfate can improve the performance of a fly ash, it also has a certain effect on the durability of the filling paste. However, at present, research into fly ash-based filling pastes is mostly focused on the properties of the paste itself and the principle of coal ash stimulation. Little attention has been paid to the influence of the filling environment on the properties of a fly ash-based filling paste. Fly ash-based filling paste contains a large amount of fly ash, and the influences of multiple factors on the behavior of fly ash filling paste when injected into the goaf are different depending on the conditions. Due to the different sulfate content of different mines, the effect of sulfate on the filling paste is also different, and the durability of the filling paste in a sulfate environment directly affects the filling effect. If the sulfate in the filling environment can be effectively used to improve the long-term stability of the filling material, this would represent a significant development in coal mine paste filling technology.

In this paper, to provide theoretical support for the study of the durability of fly ash-based filling pastes in different sulfate environments, the influence of different sulfate concentrations on the strength of a fly ash-based filling paste was analyzed using strength tests. Microstructural and compositional changes in the fly ash-based filling paste after sulfate attack were then investigated using micro-XRD analysis.

\section{Experimental Program}

\subsection{Materials}

2.1.1. Fly Ash. A grade III fly ash from a power plant in Huangdao District, Qingdao, Shandong Province, was selected. The appearance of the fly ash was grey brown, and the main chemical composition is shown in Table 1.

2.1.2. Cement. The cement used in these experiments was 32.5 ordinary Portland cement produced by Shandong Shanshui Cement Group Limited. The chemical composition of the clinker is shown in Table 2.

2.1.3. Sodium Sulfate. The sodium sulfate used in these experiments was of analytical purity, produced by Tianjin Feng Boat Chemical Reagent Technology Co., Ltd., and its sodium sulfate content was more than $99 \%$.

2.2. Selection of Material Ratio. The filling paste is made up of cementitious material and aggregate. In order to minimize the cost of filling, the optimization ratio of this mix has always been given careful attention. Coal mine safety regulations require that the initial setting time of the filling paste be $3-4 \mathrm{~h}$, the final setting time be less than $8 \mathrm{~h}$, the bleeding rate be less than $3 \%$, and the slump be in the range of $18-24 \mathrm{~cm}$. Taking the Zibo Mining Group Daizhuang Coal Mine as an example to provide an engineering background, Zhang et al. [34] determined that the ideal ratio of fly ash to cement was between 2 and 8 , and the ideal ratio of gangue to cement was between 4 and 10 . They also pointed out that when the ratio of cement, fly ash, and aggregate was 
TABle 1: Chemical contents of fly ash.

\begin{tabular}{lccccc}
\hline Loss & $\mathrm{SiO}_{2}$ & $\mathrm{Al}_{2} \mathrm{O}_{3}$ & $\mathrm{Fe}_{2} \mathrm{O}_{3}$ & $\mathrm{CaO}$ & $\mathrm{MgO}$ \\
\hline 11.62 & 52.35 & 32.60 & 2.51 & 8.13 & 0.95 \\
\hline
\end{tabular}

TABle 2: Chemical components and mineral composition of ordinary silicate cement.

\begin{tabular}{lccccccc}
\hline $\begin{array}{l}\text { Chemical } \\
\text { composition }\end{array}$ & $\mathrm{CaO}$ & $\mathrm{SiO}_{2}$ & $\mathrm{Al}_{2} \mathrm{O}_{3}$ & $\mathrm{Fe}_{2} \mathrm{O}_{3}$ & $\mathrm{MgO}$ & $\mathrm{SO}_{3}$ & $\mathrm{f}-\mathrm{CaO}$ \\
\hline Mass ratio & 62.58 & 22.95 & 5.32 & 3.90 & 2.06 & 2.33 & 0.86 \\
\hline
\end{tabular}

$1: 4: 6$, the mass concentration was $74 \%$ and the filling paste exhibited the best performance as well as good application in the field. Liu et al. [35] studied the performance of urban waste paste filling materials and also found that this ratio provided the best effect. The influence of the aggregate on the filler paste body is mainly accounted for by its particle size distribution. From a chemical point of view, the minerals in the aggregate are mostly inert, and the effect of sulfate on the performance of the aggregate is insignificant [8]. Taking into account that the impact of the groundwater environment on a filling paste is mainly on the hydration products of its cementitious material, in this study, a slurry test was used, and the ratio of cement to fly ash was set at $1: 4$. The composition of tested mixtures is shown in Table 3.

2.3. Experimental Design. Filling pastes produce different hydration products in different environments, and the quantity of generated hydration products varies significantly. As the hydration products vary, the strength of the test block will be affected to varying degrees. In this study, filling paste blocks were prepared with cement and fly ash. The strength, stress-strain curves, and hydration components of the specimens immersed in clean water and in sodium sulfate concentrations of $5 \%, 10 \%$, and $15 \%$ were analyzed to determine the mechanism of their effect on the paste strength. The test blocks were soaked in 4 sets of 12 blocks, one set soaked in each solution, for a total of 48 blocks. Within each set of twelve blocks, three blocks each were soaked for $30 \mathrm{~d}, 60 \mathrm{~d}, 90 \mathrm{~d}$, and $120 \mathrm{~d}$. In order to eliminate the influence of temperature and humidity on the strength of the test blocks, the blocks were cured under a constant relative humidity of $90 \%$ and a temperature of $25^{\circ} \mathrm{C}$. Once the blocks were demoulded, they were placed into the different solutions for soaking. The experimental design of this study is shown in Table 4 .

2.4. Experimental Steps. According to the experimental scheme, the proportion of cement to fly ash was evenly mixed at a ratio of $1: 4$, adding an appropriate amount of water to provide a mass concentration of $74 \%$. With reference to the "Standard Test Method for Long-Term Performance and Durability of Ordinary Concrete" (GB/T 50082-2009), the paste slurry was tamped into $100 \times 100 \times 100 \mathrm{~mm}$ molds, and bubbles were discharged using a shaking table. Prior to
TABle 3: The composition of tested mixtures.

\begin{tabular}{lccc}
\hline Filling materials & Cement & Fly ash & Water \\
\hline Ratio & $14.8 \%$ & $59.2 \%$ & $26 \%$ \\
\hline
\end{tabular}

destructive specimen testing, the blocks were divided into four groups: each group of test blocks was completely soaked in clean water, a $5 \%$, a $10 \%$, or a $15 \%$ sodium sulfate solution, under constant temperature conditions, until reaching the specified soaking duration of $30 \mathrm{~d}, 60 \mathrm{~d}, 90 \mathrm{~d}$, or $120 \mathrm{~d}$. The specimens were then removed from the solutions and tested for uniaxial compressive strength and analyzed by XRD. The basic operational flow chart of the experiment is shown in Figure 1 .

2.4.1. Uniaxial Compressive Strength Test. The paste test blocks were placed on an AG-X250 Shimadzu testing machine for uniaxial compression testing. The loading method used was displacement control, with the loading speed set to $0.01 \mathrm{~mm} / \mathrm{s}$. A camera was used to record the changes in the paste block during the testing process. Each test was repeated three times, and the average result was taken as the strength of the tested block. The compressive test loading process is shown in Figure 2.

2.4.2. XRD Experiment. After the uniaxial compression test was completed, samples were taken from the damaged test specimen and placed in pure ethanol to stop all hydration. After $24 \mathrm{~h}$, the sample was removed and dried at 40 centigrade in a vacuum to avoid destroying the molecular structure of the sample. The samples were ground after the drying and then passed through a $74 \mu \mathrm{m}$ sieve. The passing portion of the ground sample (i.e. the portion smaller than $74 \mu \mathrm{m}$ ) was analyzed by XRD using the instrument shown in Figure 3.

\section{Results and Discussion}

3.1. Results and Analysis of Uniaxial Compression Tests. Fly ash-based filling paste soaked in different concentrations of sulfate solution exhibited significant differences in strength. By examining the uniaxial compression strength results shown in Table 5, the changes in the strength of the filling paste specimens subjected to different conditions can be clearly seen.

As can be seen in Table 5, specimens subjected to the same conditions exhibit very similar strengths: the standard deviation in all groups was less than $0.4 \mathrm{MPa}$. Therefore, the average of the three tests of each specimen condition was taken as the uniaxial compressive strength for the given condition. For ease of comparison, one test block from each group was taken for stress-strain analysis.

3.1.1. Effect of Different Sulfate Concentrations on the Strength of the Filling Paste. As can be seen from Figure 4, with the increase in soaking time, the strength of the test blocks subjected to different soaking environments clearly 
TABle 4: Experimental design to determine the effect of sulfate on the durability of filling paste.

\begin{tabular}{lcccc}
\hline $\begin{array}{l}\text { Solid ratio } \\
\text { (cement: fly ash) }\end{array}$ & Test type & $\begin{array}{c}\text { Sample } \\
\text { specifications }\end{array}$ & $\begin{array}{c}\text { Concentration of } \\
\text { sodium sulfate solution }\end{array}$ & $\begin{array}{c}\text { Curing } \\
\text { temperature }\left({ }^{\circ} \mathrm{C}\right)\end{array}$ \\
\hline $1: 4$ & $\begin{array}{c}\text { Uniaxial compression test } \\
\text { XRD experiment }\end{array}$ & $\begin{array}{c}100 \times 100 \mathrm{~mm} \\
<74 \mu \mathrm{m}\end{array}$ & $\begin{array}{c}\text { Relative } \\
\text { humidity }(\%)\end{array}$ \\
\hline
\end{tabular}

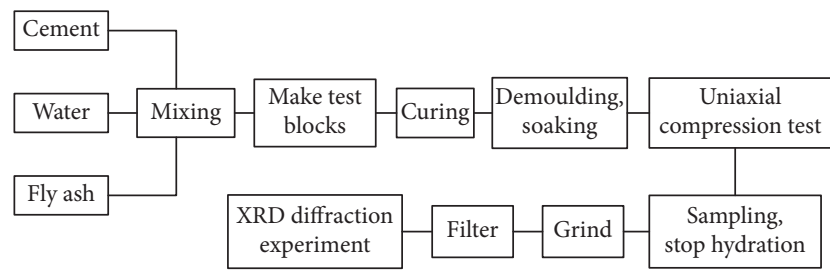

FIGURE 1: Experimental operation flow chart.

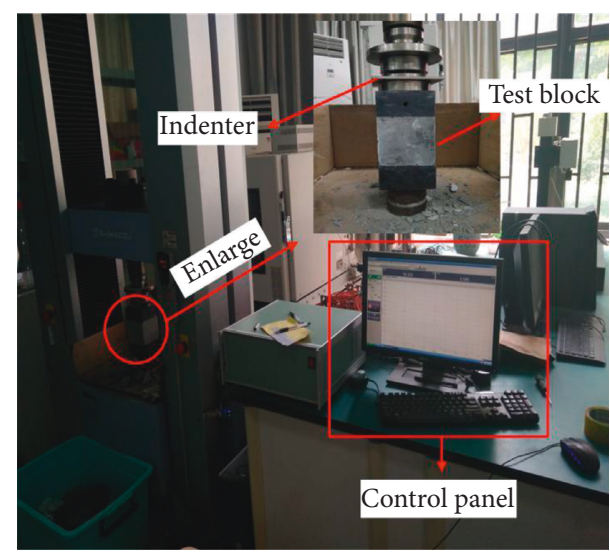

FIGURE 2: Uniaxial compression test.

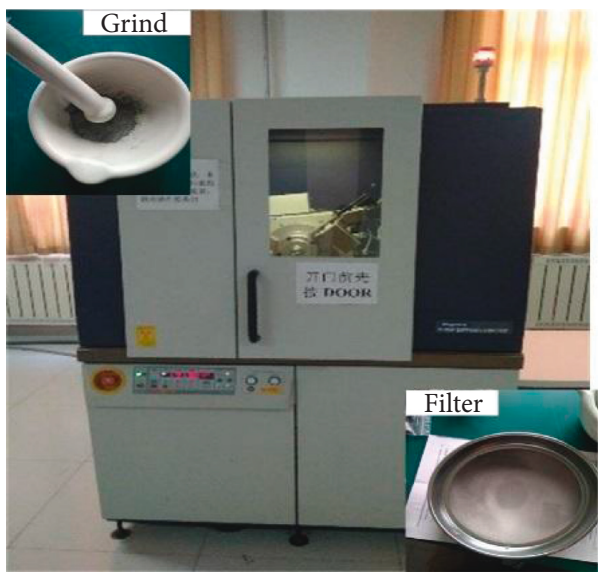

FIGURE 3: XRD analysis.

changes. With the increase in soaking time, the uniaxial compressive strength of the filling paste blocks soaked in clean water and $5 \%$ sodium sulfate solution increased. After soaking for $30 \mathrm{~d}$, the strength of the test blocks soaked in clean water were the weakest, while the strength of the test blocks soaked in the $10 \%$ sodium sulfate solution were the strongest; the average value was $11.34 \mathrm{MPa}$. After soaking for $60 \mathrm{~d}$, the strength of the test blocks soaked in the $10 \%$ sodium sulfate solution increased significantly by $37.1 \%$. The strength of the test blocks soaked in the $5 \%$ sodium sulfate solution was higher than that of the test blocks soaked in the $15 \%$ sodium sulfate solution, and the strength of test blocks soaked in clean water remained the lowest of the four soaking conditions. After soaking for $90 \mathrm{~d}$, the strength of the test blocks soaked in the $10 \%$ and $15 \%$ sodium sulfate solutions decreased, while the strength of the test blocks soaked in the $5 \%$ sodium sulfate solution increased significantly, showing a $15.6 \%$ improvement over the strength of the blocks after $60 \mathrm{~d}$ of soaking, and the strength of the test blocks soaked in clean water continued to slowly increase. After soaking for $120 \mathrm{~d}$, the strength of the test blocks soaked in clean water and in the $5 \%$ sodium sulfate tended to be steady, while that of the test blocks soaked in the $10 \%$ and $15 \%$ sodium sulfate solution continued to decrease. At this time, the strength of the test blocks soaked in the 5\% sodium sulfate solution was the highest, followed by the test blocks soaked in the clean water, and then the test blocks soaked in the $10 \%$ sodium sulfate solution, while the test blocks soaked in the $15 \%$ sodium sulfate solution exhibited the lowest strength.

The active ingredients in the filling paste that was soaked in clean water are certain; under the action of water molecules, the yield of hydrated calcium silicate and other hydration products slowly increases, therefore, the strength of the material also gradually increases, tending to slow down after the active material has completely reacted. Due to the different concentrations of sodium sulfate in the other three solutions in which the test blocks were soaked, different materials were generated. The appropriate concentration of sulfate can fully stimulate the fly ash reaction with cement clinker in the active substance, generating ettringite (AFt), which fills in the voids in the test blocks, increasing their strength. The test blocks that were soaked in the 5\% sodium sulfate solution showed an increase in strength with the increase in immersion time, showing that in this material, the sodium sulfate plays the role of an activator. When the concentration of sulfate is too high, it can accelerate the formation of AFt in the specimen at an early stage, such that the strength of the filling paste test blocks increases rapidly. With the increase in soaking time and the accompanying continuation of the reaction, the filling paste not only produces a large amount of $\mathrm{AFt}$, but the expansion of the filling paste body increases, resulting in an accompanying stress increase, reducing the strength of the filling paste, and causing the precipitation of gypsum crystals. Because of this behavior, the strengths of the test blocks soaked in the $10 \%$ and $15 \%$ sodium sulfate solutions increased more in the early soaking time than the other two groups, but their strength gradually decreased after $60 \mathrm{~d}$ of soaking. 
TABle 5: Uniaxial compressive strength of filling paste after immersion in different concentrations of sulfate solution.

\begin{tabular}{|c|c|c|c|c|c|c|c|c|c|c|c|c|c|}
\hline \multirow{2}{*}{\multicolumn{2}{|c|}{ Sulfate concentration }} & \multicolumn{12}{|c|}{ Uniaxial compressive strength $(\mathrm{MPa})$} \\
\hline & & \multicolumn{3}{|c|}{$30 \mathrm{~d}$ soaking time } & \multicolumn{3}{|c|}{$60 \mathrm{~d}$ soaking time } & \multicolumn{3}{|c|}{$90 \mathrm{~d}$ soaking time } & \multicolumn{3}{|c|}{$120 \mathrm{~d}$ soaking time } \\
\hline \multirow{3}{*}{ Clean water } & Test results & 10.27 & 9.98 & 10.08 & 12.51 & 12.67 & 13.1 & 13.92 & 13.51 & 13.76 & 14.37 & 14.66 & 14.53 \\
\hline & Mean value & & 10.11 & & & 12.76 & & & 13.73 & & & 14.52 & \\
\hline & Standard deviation & & 0.14 & & & 0.31 & & & 0.21 & & & 0.15 & \\
\hline \multirow{3}{*}{$5 \%$} & Test results & 10.32 & 10.61 & 10.81 & 13.42 & 13.56 & 13.82 & 15.92 & 15.51 & 15.73 & 15.95 & 16.32 & 16.11 \\
\hline & Mean value & & 10.58 & & & 13.60 & & & 15.72 & & & 16.13 & \\
\hline & Standard deviation & & 0.25 & & & 0.29 & & & 0.21 & & & 0.19 & \\
\hline \multirow{3}{*}{$10 \%$} & Test results & 10.97 & 11.55 & 11.5 & 15.31 & 15.97 & 15.37 & 14.52 & 14.91 & 15.24 & 12.96 & 13.89 & 14.04 \\
\hline & Mean value & & 11.34 & & & 15.55 & & & 14.89 & & & 13.63 & \\
\hline & Standard deviation & & 0.32 & & & 0.36 & & & 0.36 & & & 0.34 & \\
\hline \multirow{3}{*}{$15 \%$} & Test results & 10.57 & 10.88 & 11.07 & 13.31 & 13.67 & 13.64 & 12.92 & 12.51 & 12.31 & 12.16 & 11.62 & 11.41 \\
\hline & Mean value & & 10.84 & & & 13.54 & & & 12.58 & & & 11.73 & \\
\hline & Standard deviation & & 0.25 & & & 0.20 & & & 0.31 & & & 0.39 & \\
\hline
\end{tabular}

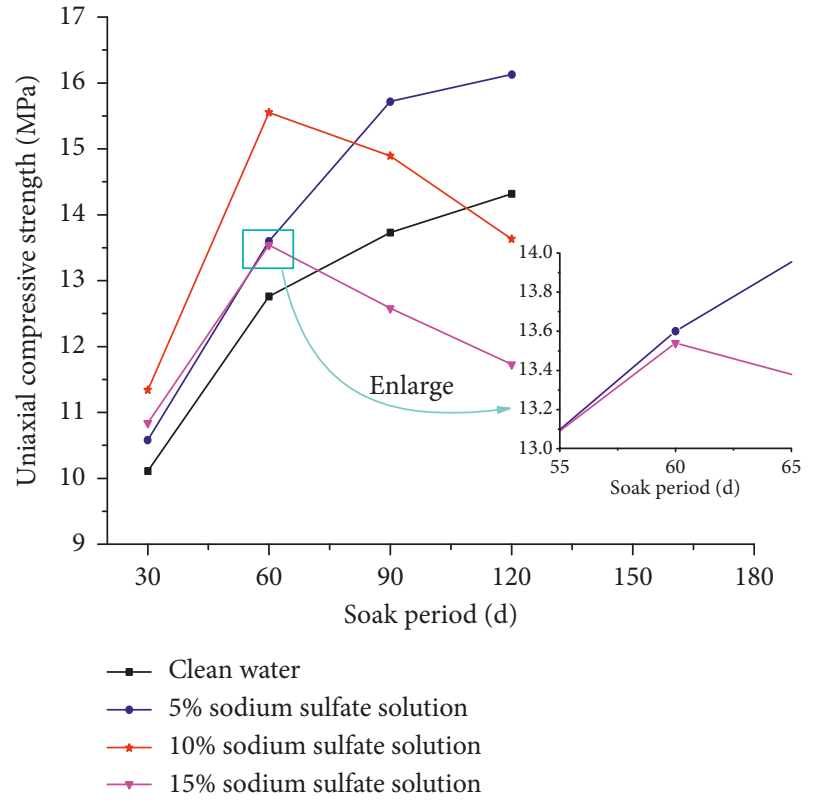

FIGURE 4: Effect of different concentrations of sulfate solution on the strength of filling paste.

\subsubsection{Stress-Strain Analysis of Test Blocks in Different Soaking}

Time. It can be seen in Figure 5 that after soaking for $30 \mathrm{~d}$, the peak stress in the filling paste test blocks soaked in the $15 \%$ sodium sulfate solution was larger than for the other three groups, while the elastic modulus was the smallest. After soaking for $60 \mathrm{~d}$, the peak stress in each group increased, and the peak stress in test blocks soaked in clean water remained the lowest. At this time, the peak stress and stiffness of the filling paste test blocks soaked in the $10 \%$ sodium sulfate solution reached their maximum, indicating an elastic modulus of nearly $1000 \mathrm{MPa}$. The test block soaked in the $15 \%$ sodium sulfate solution exhibited delayed damage after reaching a strain of $1.7 \%$, while the stress was still rising. After soaking for $90 \mathrm{~d}$, the peak stress in the test blocks soaked in clean water and in the $5 \%$ sodium sulfate solution showed significant increase, while the peak stresses in the other two groups decreased relatively. The filling paste blocks soaked in $10 \%$ sodium sulfate solution also exhibited delayed failure phenomenon at $90 \mathrm{~d}$, but at a failure stress, it was lower than that of the filling paste blocks soaked in the $15 \%$ sodium sulfate solution. After soaking for $120 \mathrm{~d}$, the peak stress in the test blocks soaked in the $5 \%$ sodium sulfate solution was the highest (about 10\% higher than the test blocks soaked in clean water), while the peak stress in the test blocks soaked in the other two solutions was significantly reduced. The test blocks soaked in the $10 \%$ sodium sulfate solution exhibited delayed failure at a strain of $2.60 \%$, after which the stress continued to rise. The test blocks soaked in the $15 \%$ sodium sulfate solution reached their peak at a strain of $1.75 \%$ and then maintained a certain residual strength as the stress slowly decreased.

Under different soaking times and different concentrations of sulfate solution, the stress and strain characteristics of the filling paste test blocks are obviously different, and the elastic modulus is irregular. After peak stress, all filling paste test blocks maintained a certain residual strength. This is because the filling paste test blocks contain plain concrete. Before damage, the test blocks first undergo a compaction strengthening stage before entering the elastic stage. The cracks produced after the rupture then appear in alternately staggered rows, with shards flaking around the test block core (Figure 6). Because of this behavior, the stress continues to be borne by the core of the block, and thus will not fall as sharply as it does when rock is subjected to similar damage.

The filling paste test blocks produce different substances at different stages of soaking. The early absorption of sodium sulfate provides sufficient $\mathrm{SO}_{4}{ }^{2-}$ for the filling paste, generating AFt to fill the internal voids in the test block matrix. This indicates that for sulfate concentrations in a certain range, the filling paste block strength increases with the increase in sulfate concentration. After peak stress is achieved, there remains a certain residual strength, and the stress decreases slowly. The presence of excessive AFt can cause the internal stress in the filling paste test block to increase, resulting in microcracks, leading to a decrease in the strength of the test blocks. Therefore, when subjected to uniaxial compression, the test blocks soaked in a solution 


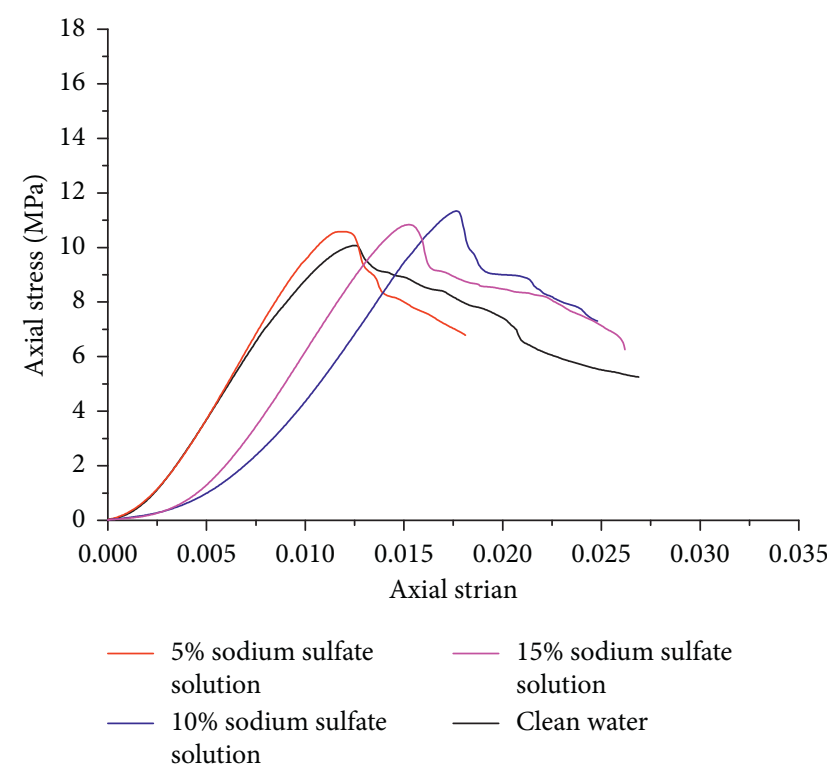

(a)

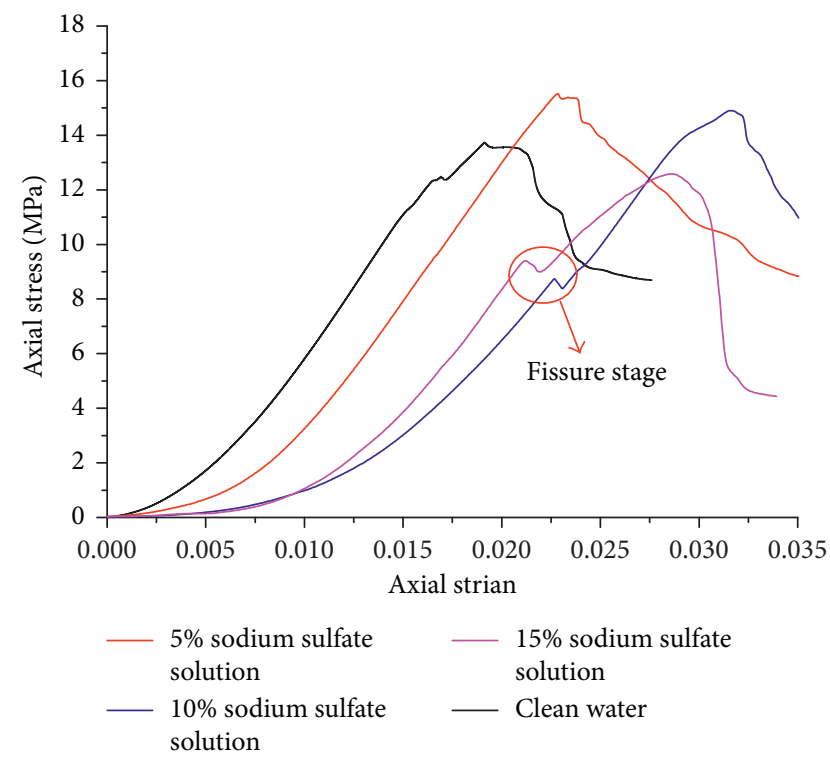

(c)

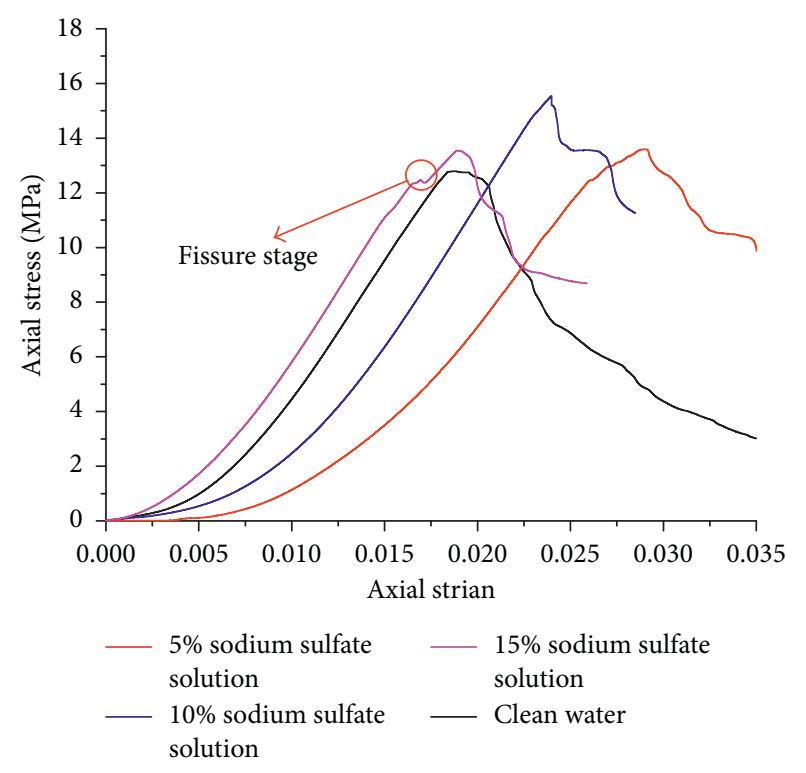

(b)

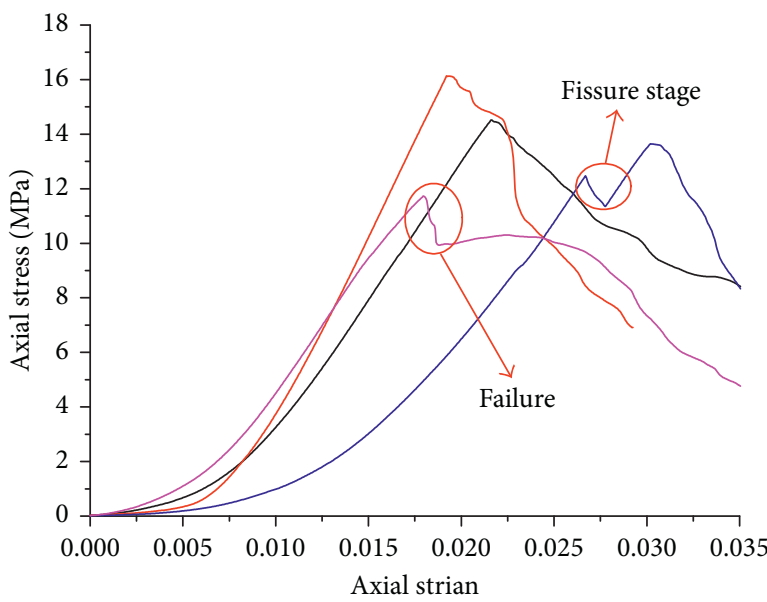

$\begin{array}{ll}-5 \% \text { sodium sulfate } & -15 \% \text { sodium sulfate } \\ \text { solution } & \text { solution } \\ & 10 \% \text { sodium sulfate } \\ \text { solution } & - \text { Clean water }\end{array}$

(d)

FIgURE 5: Stress-strain curves of each group for each soaking period: (a) $30 \mathrm{~d}$; (b) $60 \mathrm{~d}$; (c) $90 \mathrm{~d}$; (d) $120 \mathrm{~d}$.

with a high concentration of sulfate will first manifest a cracking stage, indicating strain energy release, and then enter into a compaction stage before finally reaching the peak stress and destroying the test block.

3.2. Results of XRD Analysis. Through the results of the strength testing of the test blocks soaked in varying sodium sulfate solutions, it was found that the differences in the solution concentration and soaking time had a significant effect on the filling paste test block strengths. To better understand these effects, XRD was used to analyze the hydration products and explore the regularity of the paste changes. Figure 7 shows the XRD pattern of the hydrated products in the filling paste soaked in different solutions for different periods of time.

As shown in Figure 7(a), after soaking in the four different solutions for $30 \mathrm{~d}$, the strongest peak in the XRD analysis of the test samples is observed for $\mathrm{SiO}_{2}$, indicating that there is still a great deal of cement and fly ash that has not yet been hydrated in the filling paste. At this time, the main products in the test blocks soaked in clean water are $\mathrm{Ca}$ $(\mathrm{OH})_{2}$, hydrated calcium silicate $(\mathrm{C}-\mathrm{S}-\mathrm{H})$, hydrated calcium aluminate $(\mathrm{C}-\mathrm{A}-\mathrm{H})$, and hydrated calcium aluminosilicate (C-A-S-H). With the addition of sodium sulfate in the soaking solution and with the increase in its concentration, the peak value of $\mathrm{SiO}_{2}$ and $\mathrm{C}-\mathrm{A}-\mathrm{H}$ in the test blocks gradually decreased and $\mathrm{Ca}(\mathrm{OH})_{2}$ disappeared, accompanied by 


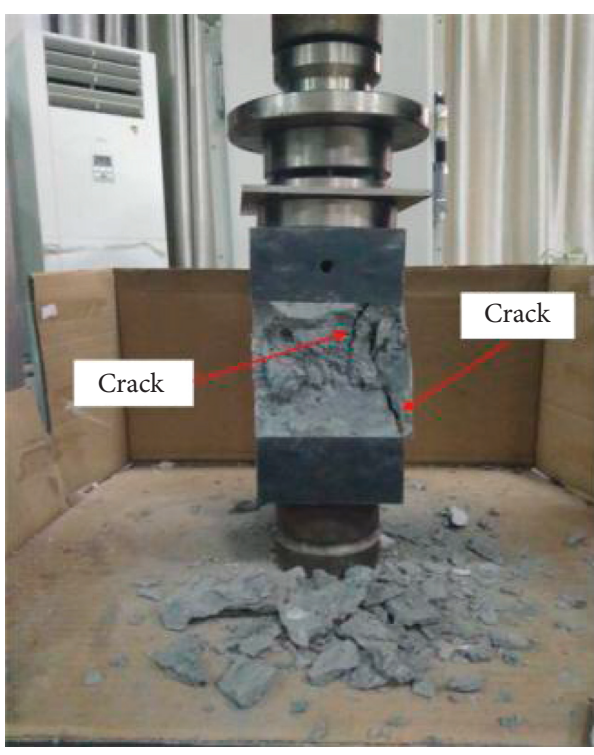

(a)

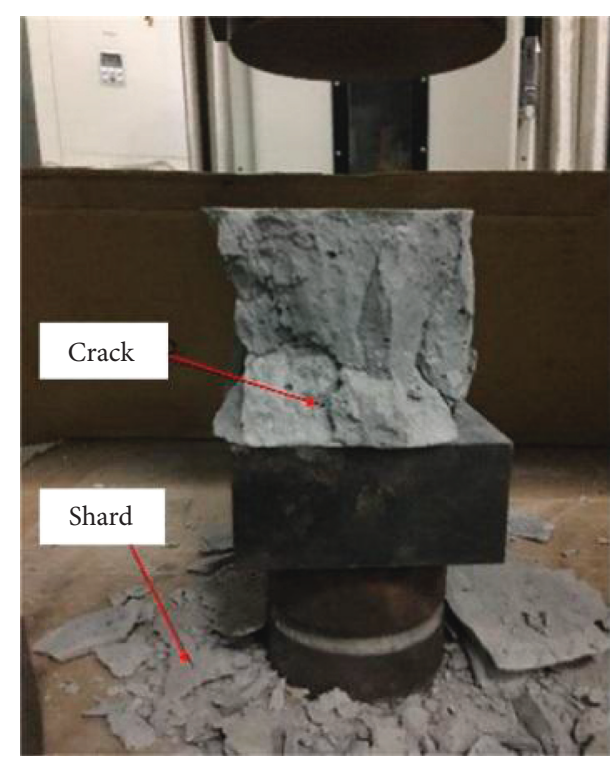

(b)

Figure 6: Typical condition of a test block after destruction: (a) cracking; (b) flaking and peeling.

the formation of AFt. These changes are mainly due to the addition of the sodium sulfate, providing $\mathrm{SO}_{4}{ }^{2-}$ for the production of $\mathrm{AFt}$ and consuming a large quantity of products such as $\mathrm{Ca}(\mathrm{OH})_{2}$ and $\mathrm{C}-\mathrm{A}-\mathrm{H}$. It can be inferred that in the early stages of soaking in sodium sulfate, AFt was produced inside the filling paste test blocks and filled in the internal voids, making the test blocks denser and thus stronger. This inference is supported by the fact that for a soaking time of $30 \mathrm{~d}$, the strength of the test blocks soaked in the clean water was lower than that of the test blocks soaked in the sulfate solution, and within a certain sulfate range, the strength of the filling paste blocks increased with the increase in sulfate concentration.

In Figure 7(b), it can be seen that when the filling paste test blocks were soaked for $60 \mathrm{~d}$, the diffraction peaks of the samples of each test set obviously grew in number, and the peak value of $\mathrm{SiO}_{2}$ exhibited a downward trend. Compared with the samples soaked for $30 \mathrm{~d}$, the number of C-S-H peaks of the samples soaked in clean water increased significantly, indicating that a large amount of hydrated calcium silicate was already produced in the filling paste to provide strength. A significant AFt peak appeared in the filling pastes soaked in sodium sulfate solutions. With the increase in sulfate concentration, the intensity of the AFt peak increased. At $60 \mathrm{~d}$, the intensity of the AFt peak of the test blocks soaked in the $10 \%$ sodium sulfate solution was the largest, as was the uniaxial compressive strength, indicating that a proper amount of AFt can enhance the strength of the filling paste. However, gypsum began to appear in the test blocks that were soaked in the $15 \%$ sodium sulfate solution, and these blocks exhibited the lowest uniaxial compressive strength of all test blocks soaked for this duration, indicating that excessive $\mathrm{SO}_{4}{ }^{2-}$ leads to the creation of expansive gypsum inside the filling paste, reducing its strength.

After soaking for $90 \mathrm{~d}$, the uniaxial compressive strength of the test blocks decreased for larger concentrations of sulfate in the soaking solution. At this time, the strength of the test blocks soaked in the $5 \%$ sodium sulfate solution was the greatest. As can be seen from Figure 7(c), the larger the sulfate concentration, the higher the AFt peak exhibited in the XRD pattern of the hydration products in the test blocks. This means that the filling paste has generated a large amount of AFt by this time, which increases the internal stress in the test blocks while filling the voids in the block matrix. As this process continues, more microcracks are generated, thereby reducing the strength of the filling paste. The quantity of gypsum in the test blocks that were soaked in the $15 \%$ sodium sulfate solution showed a relative increase, and the test blocks soaked in the $10 \%$ sodium sulfate solution also indicated that gypsum was generated. This phenomenon suggests that a high concentration of sulfate can produce a large amount of gypsum in the filling paste, reducing its strength. The strength of the test blocks soaked in clean water was relatively improved after $90 \mathrm{~d}$, and the peak value of $\mathrm{SiO}_{2}$ in the XRD pattern was reduced. However, the diffraction peaks of gelling materials such as hydrated calcium silicate, hydrated calcium aluminate, and hydrated calcium aluminosilicate showed a significant increase, indicating that, as the hydration reaction progresses, large amounts of the $\mathrm{SiO}_{2}$ in the filling paste are consumed to form hydrated calcium silicate and other gelling substances, which enhance the strength of the filling paste blocks.

After soaking for 120 days, the strength of the test blocks soaked in water and the 5\% sodium sulfate solution still indicated a slow increase in strength. However, the uniaxial compressive strength of the test blocks soaked in the $10 \%$ and $15 \%$ sodium sulfate solutions decreased significantly. As can be seen from Figure 7(d), the XRD pattern of the test blocks soaked in the $10 \%$ and $15 \%$ sodium sulfate solutions shows significant increases in the AFt and gypsum peaks. This indicates that the mass production of AFt and gypsum affects the strength of the filling paste test blocks, and as such 


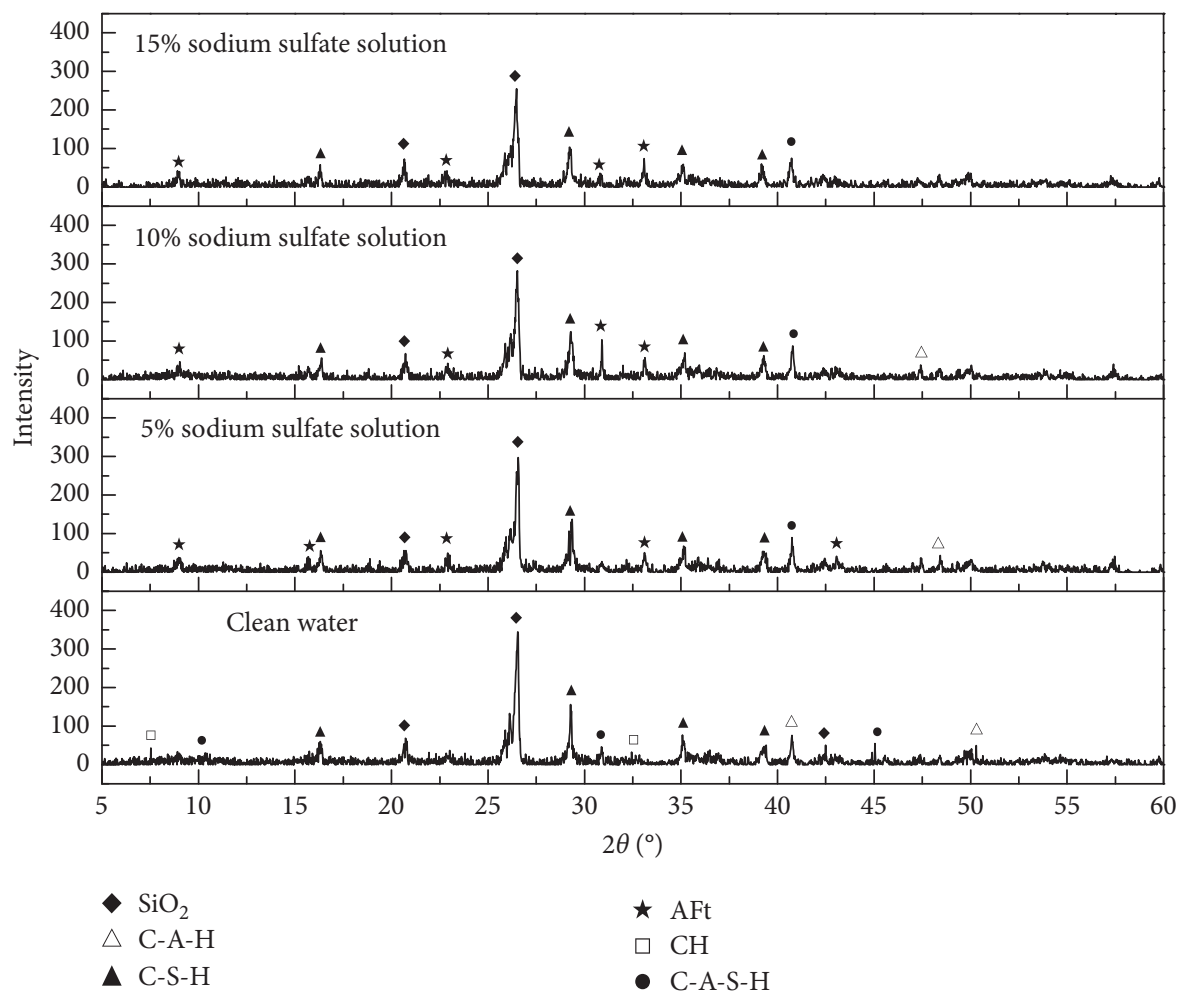

(a)

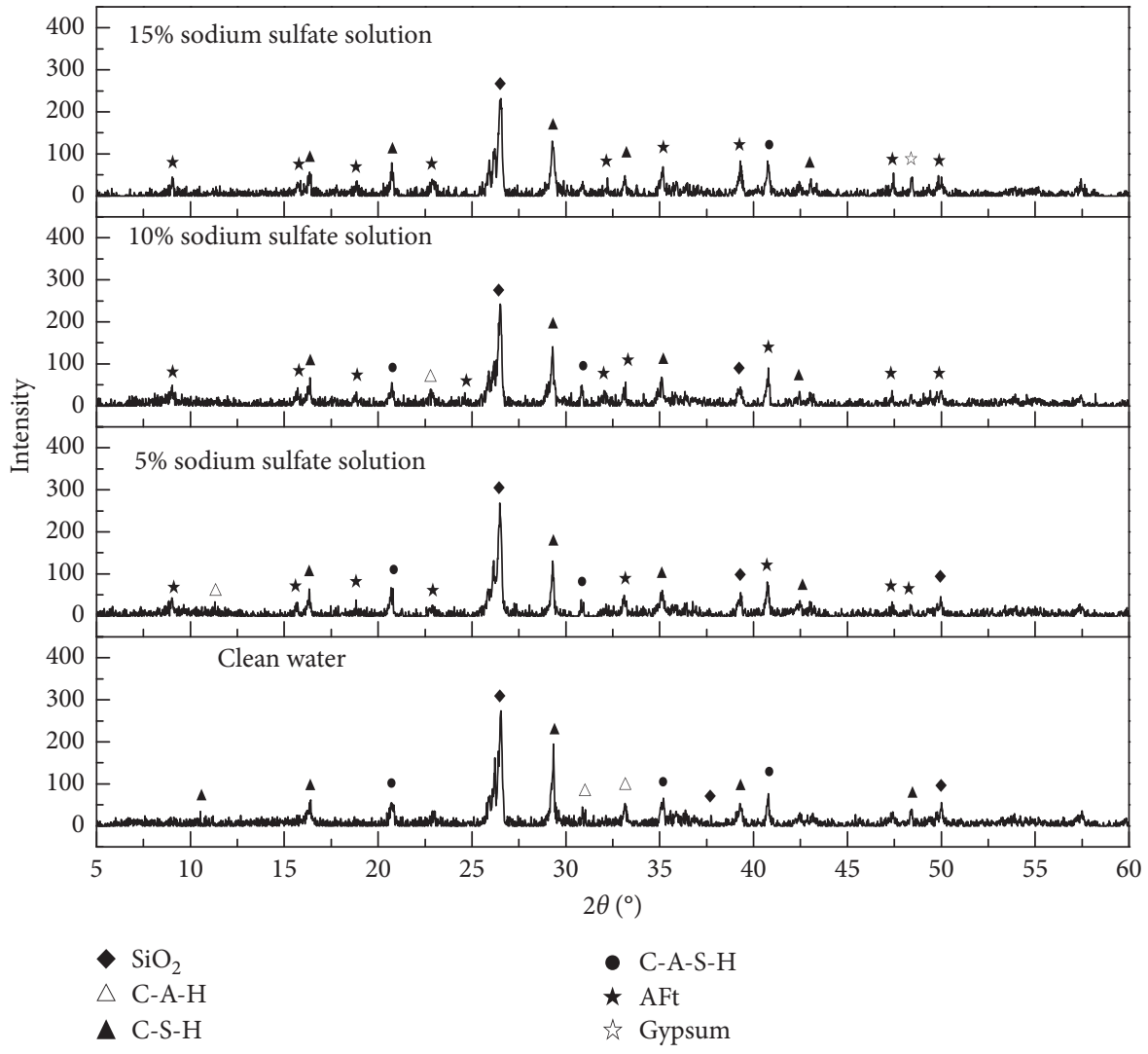

(b)

Figure 7: Continued. 


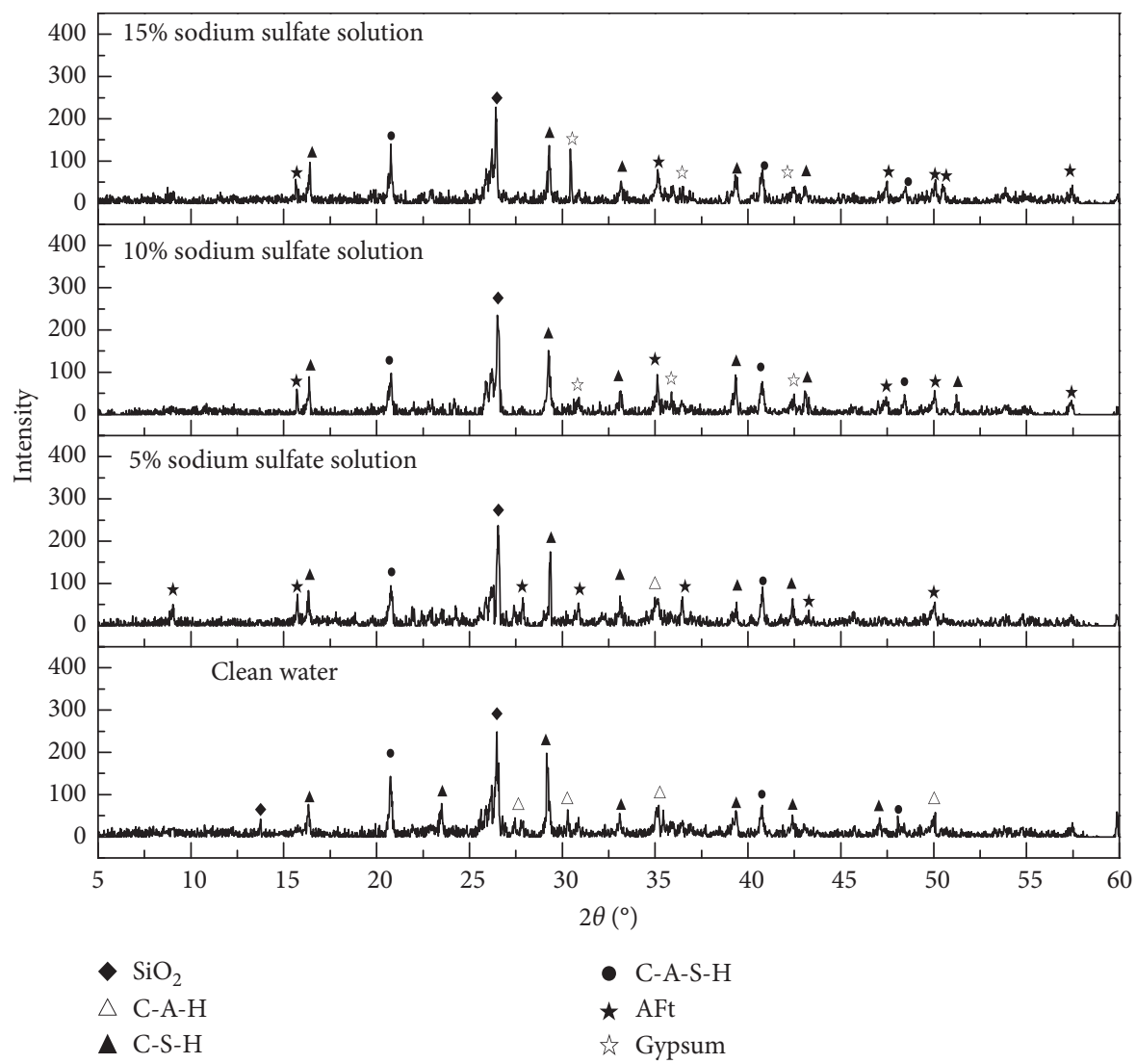

(c)

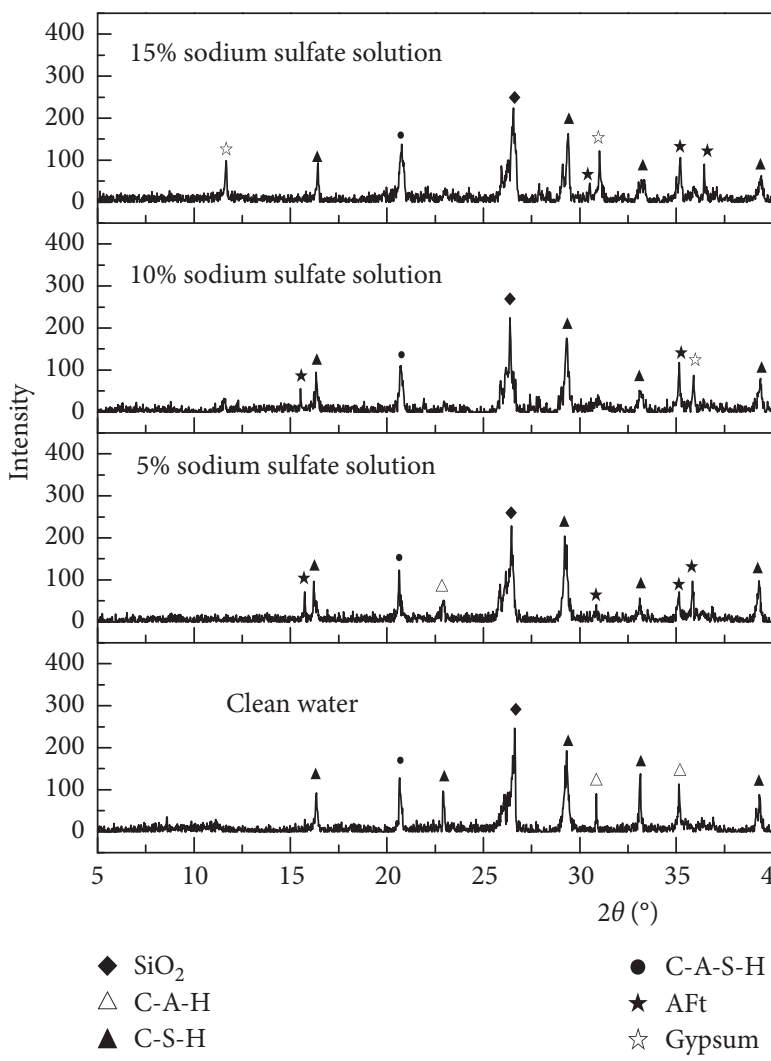

(d)

FIGURE 7: XRD patterns of hydrated products of filling paste in each immersion solution for each soaking period: (a) $30 \mathrm{~d}$; (b) $60 \mathrm{~d}$; (c) $90 \mathrm{~d}$; (d) $120 \mathrm{~d}$. 
it is not conducive to the filling of mines. However, when the filling paste was soaked in the $5 \%$ sodium sulfate solution, there was no gypsum formed in the filling paste, and there was a small amount of $\mathrm{C}-\mathrm{A}-\mathrm{H}$. This formation of the appropriate amount of AFt provides a higher strength than the other two sulfate-soaked test blocks. The test blocks soaked in clean water indicated that the hydrated calcium silicate, hydrated calcium aluminate, and hydrated calcium aluminate peaks had been enhanced but not to a significant degree. This suggests that because the change in product intensity is so gentle, the internal filling paste hydration is nearing saturation.

Figure 7 demonstrates that, for the same soaking period, the XRD patterns of the hydration products of filling pastes soaked in different solutions were similar, but the quantities of hydration products were different. For the same soaking solution and different soaking periods, the same XRD peaks for hydration products exhibited larger differences. The differences in the quantity of these hydration products have a significant effect on the strength of the filling pastes during each soaking period.

\subsection{Action Mechanism of Sulfate in Fly Ash-Based Filling} Paste. The influence of sulfate on the strength of fly ashbased filling paste is mainly determined by the hydration products. A large number of active $\mathrm{SiO}_{2}$ and $\mathrm{Al}_{2} \mathrm{O}_{3}$ exist in fly ash, which only have potential cementitious activity. Without an activator, these substances do not generally produce gelling.

In an environment without sulfate, the $\mathrm{Ca}(\mathrm{OH})_{2}$ generated by the hydration of the cement clinker provides an alkaline environment for the fly ash. The Si-O and Al-O bonds in the components are broken, and the glass phase is gradually dissolved. The silicon oxides in the vitreous body begin to hydrate, forming a large amount of C-S-H and $\mathrm{C}-\mathrm{A}-\mathrm{H}$, providing strength for the cementing system. The chemical equation of this process is given as follows [26]:

$$
\begin{aligned}
& \mathrm{SiO}_{2}+\mathrm{Ca}(\mathrm{OH})_{2}+\mathrm{H}_{2} \mathrm{O} \longrightarrow \mathrm{CaO} \cdot \mathrm{SiO}_{2} \cdot x \mathrm{H}_{2} \mathrm{O} \\
& \mathrm{Al}_{2} \mathrm{O}_{3}+\mathrm{Ca}(\mathrm{OH})_{2}+\mathrm{H}_{2} \mathrm{O} \longrightarrow \mathrm{CaO} \cdot \mathrm{Al}_{2} \mathrm{O}_{3} \\
& \cdot x \mathrm{H}_{2} \mathrm{O} \\
& \mathrm{Al}_{2} \mathrm{O}_{3}+\mathrm{Ca}(\mathrm{OH})_{2}+2 \mathrm{SiO}_{2}+3 \mathrm{H}_{2} \mathrm{O} \longrightarrow \mathrm{CaO} \cdot \mathrm{Al}_{2} \mathrm{O}_{3} \\
& \cdot 2 \mathrm{SiO}_{3} \cdot 4 \mathrm{H}_{2} \mathrm{O}
\end{aligned}
$$

The XRD analysis indicated that with the increase in soaking time, the $\mathrm{C}-\mathrm{S}-\mathrm{H}$ and $\mathrm{C}-\mathrm{A}-\mathrm{H}$ diffraction peaks increased, which has an inevitable connection to the increase in strength. Compared to the test blocks soaked in clean water, there are many more AFt formations in the hydration products of the paste test blocks soaked in sodium sulfate solutions, and the amount of AFt produced also affects the strength of the paste. After the sulfate ions enter the interior of the filling paste, they can react with the unreacted $\mathrm{Ca}(\mathrm{OH})_{2}$ to generate calcium sulfate, then calcium sulfate reacts with hydrated calcium aluminate $\left(4 \mathrm{CaO} \cdot \mathrm{Al}_{2} \mathrm{O}_{3} \cdot 13 \mathrm{H}_{2} \mathrm{O}\right)$ in the fly ash and cement to form hydrated calcium sulfoaluminate, that is, AFt. The reaction equation is as follows [36]:

$$
\begin{gathered}
4 \mathrm{CaO} \cdot \mathrm{Al}_{2} \mathrm{O}_{3} \cdot 13 \mathrm{H}_{2} \mathrm{O}+3\left(\mathrm{CaSO}_{4} \cdot 2 \mathrm{H}_{2} \mathrm{O}\right)+14 \mathrm{H}_{2} \mathrm{O} \\
\longrightarrow 3 \mathrm{CaO} \cdot \mathrm{Al}_{2} \mathrm{O}_{3} \cdot 3 \mathrm{CaSO}_{4} \cdot 32 \mathrm{H}_{2} \mathrm{O}+\mathrm{Ca}(\mathrm{OH})_{2}
\end{gathered}
$$

Because AFt can be stably present and exhibits expandability, a small amount of sulfate ion-generated AFt can fill the gaps in the interior of the paste, increasing the strength of the paste. However, the excessive formation of AFt expands the filling paste, increasing the internal stress and reducing strength. Therefore, in the early stages of soaking, the strengths of the paste blocks soaked in sodium sulfate solutions are relatively high. With the increase in soaking time, the strength of the test blocks soaked in highconcentration sodium sulfate solutions decreases, indicating that when the $\mathrm{SO}_{4}{ }^{2-}$ is too high in the groundwater environment in which the filling paste is applied, gypsum crystals will be precipitated. The reaction equation is as follows [37]:

$$
\mathrm{Ca}(\mathrm{OH})_{2}+\mathrm{SO}_{4}^{2-}+2 \mathrm{H}_{2} \mathrm{O} \longrightarrow \mathrm{CaSO}_{4} \cdot 2 \mathrm{H}_{2} \mathrm{O}+2 \mathrm{OH}^{-}
$$

Filling pastes soaked in the $10 \%$ and $15 \%$ sodium sulfate solutions will produce gypsum in the later stages of soaking, and their strengths will decrease accordingly. This demonstrates that the production of gypsum has a negative influence on the strength of the filling paste. The formation of gypsum increases the volume of the filling paste, and internal expansion stress is produced in the filling body, leading to damage of the test blocks. At the same time, the consumption of $\mathrm{Ca}(\mathrm{OH})_{2}$ inside the filling paste decomposes the gelling substances generated within the paste, further reducing its strength.

\section{Conclusions}

A series of filling paste test blocks were soaked in varying concentrations of sodium sulfate solutions for varying durations. The uniaxial compressive strengths of the blocks were then determined, and XRD analyses of the constituent materials of the pastes were conducted to identify the products present in the paste material. The testing program resulted in the following conclusions:

(1) In the early stages of immersion, the uniaxial compressive strength of the filling paste test blocks soaked in $10 \%$ sodium sulfate solution was the highest. With the increase in soaking time, the uniaxial compressive strengths of the test blocks soaked in clean water and the $5 \%$ sodium sulfate solution were improved, while the strength of the filled paste test blocks soaked in the $10 \%$ and $15 \%$ sodium sulfate solutions decreased after soaking for $60 \mathrm{~d}$.

(2) After soaking for $120 \mathrm{~d}$, the uniaxial compressive strength of the filling paste test blocks soaked in the $5 \%$ sodium sulfate solution was the highest, indicating that an appropriate concentration of sodium sulfate in the soaking solution acts as an activator for the fly ash in the filling paste. 
(3) The stress-strain curves indicate that the elastic moduli of the filling paste test blocks change irregularly. After soaking for $60 \mathrm{~d}$, the strength of the filling pastes soaked in a higher concentration than the $5 \%$ sodium sulfate solution began to display microcracks, affecting the strength of the test blocks.

(4) It can be seen from the XRD patterns that the main hydration product generated in the filling paste was $\mathrm{C}-\mathrm{S}-\mathrm{H}$. The main product generated in the filling paste test blocks soaked in the sodium sulfate solution was initially AFt, though with the increase in the concentration of sodium sulfate and soaking time, gypsum crystals appeared in the filling paste, which are detrimental to the strength of the test blocks.

(5) A concentration of 5\% sodium sulfate is helpful for improving the strength of a fly ash-based filling paste. Sodium sulfate solutions with concentrations of $10 \%$ and $15 \%$ increased the early strength of the filling paste faster, but with the continued increase in AFt and gypsum crystals after longer soaking durations, the strength decreased, and thus sulfate concentrations of this intensity are not conducive to the durability of a fly ash-based filling paste.

This research has determined that the presence of sulfate in mine water can be useful to the properties of filling pastes containing fly ash. However, the concentrations of sulfates in the subject mine must be carefully determined, as excessive concentrations of sulfates can lead to detrimental effects of the strength of the filling paste. By quantifying the behaviors of fly ash-based filling pastes in sulfate environments, this research has defined how this material can be successfully applied to coal mine filling.

\section{Data Availability}

All data are available within the article or from the corresponding author upon request.

\section{Conflicts of Interest}

The authors declare that they have no conflicts of interest.

\section{Acknowledgments}

This research was supported by China Coal Industry Association Science and Technology Research Guidance Project (MTKJ2016-277) and received grants from the Natural Science Foundation of Shandong Province (ZR2017MEE055), Key Project of Green and High Efficiency Mining and Comprehensive Utilization of Mineral Resources in Henan Province (s201609).

\section{References}

[1] Q. L. Chang, H. Q. Zhou, J. B. Bai et al., "Study and practice of overburden stability of paste filling and mining," Journal of Mining and Safety Engineering, vol. 28, no. 2, pp. 279-282, 2011.
[2] S. J. Chen, D. W. Yin, F. W. Cao, Y. Liu, and K. Ren, "An overview of integrated surface subsidence-reducing technology in mining areas of China," Natural Hazards, vol. 81, no. 2, pp. 1129-1145, 2016.

[3] J. L. Xu, Q. You, W. B. Zhu, X. S. Li, and W. Q. Lai, "The theoretical study of strip filling control mining subsidence," Journal of China Coal Society, vol. 32, no. 2, pp. 119-122, 2007.

[4] H. J. Zhao, F. S. Ma, Y. M. Zhang, and J. Guo, "Monitoring and mechanisms of ground deformation and ground fissures induced by cut-and-fill mining in the Jinchuan Mine 2, China," Environmental Earth Sciences, vol. 68, no. 7, pp. 1903-1911, 2013.

[5] W. B. Zhu, J. M. Xu, J. L. Xu, D. Y. Chen, and J. X. Shi, "Piercolumn backfill mining technology for controlling surface subsidence," International Journal of Rock Mechanics and Mining Sciences, vol. 96, pp. 58-65, 2017.

[6] Y. Liu, Y. Lu, H. Guo, and B. Q. Cui, "Experimental study on proportion optimization of construction waste paste filling materials," Safety in Coal Mines, vol. 48, no. 6, pp. 65-68, 2017.

[7] M. G. Qian, J. L. Xu, and X. X. Miu, "Coal mine green mining technology," Journal of China University of Mining and Technology, vol. 32, no. 4, pp. 343-348, 2003.

[8] W. C. Li, Characteristics and mechanism of sulphate effect on the early age properties of cemented paste backfill, Ph.D. dissertation, China University of Mining \& Technology, Beijing, China, 2016.

[9] H. Q. Zhang, Y. Liu, and Q. F. Wang, "Study on performance of filling with urban construction waste," Mining Research and Development, vol. 34, no. 4, pp. 37-39, 2014.

[10] W. M. Cheng, X. M. Hu, J. Xie, and Y. Y. Zhao, “An intelligent gel designed to control the spontaneous combustion of coal: fire prevention and extinguishing properties," Fuel, vol. 210, pp. 826-835, 2017.

[11] Z. D. Cui and H. H. Sun, "The preparation and properties of coal gangue based sialite paste-like backfill material," Journal of China Coal Society, vol. 35, no. 6, pp. 896-899, 2010.

[12] O. Nasir and M. Fall, "Shear behavior of cemented pastefill-rock interfaces," Engineering Geology, vol. 101, no. 3-4, pp. 146-153, 2008.

[13] T. Y. Qi, G. R. Feng, Y. X. Guo et al., "Experimental study on the changes of coal paste backfilling material performance during hydration process," Journal of Mining and Safety Engineering, vol. 32, no. 1, pp. 42-48, 2015.

[14] Z. C. Wang, H. C. Xia, and H. F. Wang, "Analysis of hydration mechanism and microstructure of composite cementitious materials for filling mining," Journal of Wuhan University of Technology, vol. 32, no. 4, pp. 910-913, 2017.

[15] Y. Li, R. J. Wang, F. Yan, X. He, and Y. Sun, "Effect of fly ash on frost resistance and sulfate resistance of concrete," Journal of Northwest $A$ and F University, vol. 45, no. 2, pp. 219-226, 2017.

[16] M. Fall, J. Célestin, and F. Han, "Suitability of bentonite-paste tailings mixtures as engineering barrier material for mine waste containment facilities," Minerals Engineering, vol. 22, no. 9-10, pp. 840-848, 2009.

[17] A. Ren, G. R. Feng, Y. X. Guo et al., "Influence on performance of coal mine filling paste with fly ash," Journal of China Coal Society, vol. 39, no. 12, pp. 2374-2380, 2014.

[18] R. Rani and M. K. Jain, "Effect of bottom ash at different ratios on hydraulic transportation of fly ash during mine fill," Powder Technology, vol. 315, no. 4, pp. 309-317, 2017. 
[19] M. Fall and S.S. Samb, "Effect of high temperature on strength and microstructural properties of cemented paste backfill," Fire Safety Journal, vol. 44, no. 4, pp. 642-651, 2009.

[20] D. Wu, Y. B. Hou, T. F. Deng, Y. Z. Chen, and X. L. Zhao, "Thermal, hydraulic and mechanical performances of cemented coal gangue-fly ash backfill," International Journal of Mineral Processing, vol. 162, no. 3, pp. 12-18, 2017.

[21] Q. F. Wang, Y. Liu, H. Q. Zhang, and N. Jiang, "Durability test of gangue paste stowing material," Coal Mining Technology, vol. 19, no. 1, pp. 3-6, 2014.

[22] M. Gao, Study on deterioration mechanism of cement-based rich-water material in corrosive environment, Ph.D. dissertation, University of Science and Technology, Beijing, China, 2017.

[23] Q. Sun, X. L. Li, X. Wei, and Q.W. Mu, "Experimental study on the influence of mine water corrosion over filling paste strength," Bulletin of the Chinese Ceramic Society, vol. 34, no. 5, pp. 1246-1251, 2015.

[24] G. R. Feng, Y. F. Ren, X. Y. Zhang et al., "The activating experimental research of fly ash for mining filling material in Tashan Mine," Journal of China Coal Society, vol. 36, no. 5, pp. 732-737, 2011.

[25] X. L. Guo, H. S. Shi, and W. A. Dick, "Utilization of thermally treated flue gas desulfurization (FGD) gypsum and class-C Fly Ash (CFA) to prepare CFA-based geopolymer," Journal of Wuhan University of Technology, vol. 28, no. 1, pp. 132-138, 2013.

[26] T. S. He and G. Q. Wei, "Effect of activators excitated cement specimen with different amount of fly ash on strength," Concrete, vol. 235, no. 5, pp. 62-64, 2009.

[27] G. J. Ke, X. F. Yang, H. Peng et al., "Progress of research on chemical activating mechanisms of fly ash," Journal of China Coal Society, vol. 30, no. 3, pp. 366-370, 2005.

[28] M. Fall and M. Benzaazoua, "Modeling the effect of sulphate on strength development of paste backfill and binder mixture optimization," Cement and Concrete Research, vol. 35, no. 2, pp. 301-314, 2005.

[29] M. Pokharel and M. Fall, "Combined influence of sulphate and temperature on the saturated hydraulic conductivity of hardened cemented paste backfill," Cement and Concrete Composites, vol. 38, no. 3, pp. 21-28, 2013.

[30] M. Fall and M. Pokharel, "Coupled effects of sulphate and temperature on the strength development of cemented tailings backfills: Portland cement-paste backfill," Cement and Concrete Composites, vol. 32, no. 10, pp. 819-828, 2010.

[31] J. H. Liu, M. Gao, and A. X. Wu, "Corrosion and deterioration mechanism of water-rich filling materials in acid solution," Chinese Journal of Engineering, vol. 38, no. 9, pp. 1212-1220, 2016.

[32] Q. Sun, X. L. Li, and X. Wei, "Study on creep property of paste filling material under sulfate corrosion," Journal of Safety Science and Technology, vol. 11, no. 3, pp. 12-18, 2015.

[33] W. C. Li and M. Fall, "Sulphate effect on the early age strength and self-desiccation of cemented paste backfill," Construction and Building Materials, vol. 106, no. 12, pp. 296-304, 2016.

[34] X. G. Zhang, J. Lin, J. X. Liu, F. Li, and Z. Z. Pang, "Investigation of hydraulic-mechanical properties of paste backfill containing coal gangue-fly ash and its application in an underground coal mine," Energies, vol. 10, no. 9, p. 1309, 2017.
[35] Y. Liu, Experimental study on the performance of paste backfilling materials with construction waste recycled aggregate, Ph.D. dissertation, University of Science and Technology, Shandong, China, 2013.

[36] G. S. Li, "Sulfate resistance of fly ash concrete (English)," Journal of the Chinese Ceramic Society, vol. 40, no. 1, pp. 39-48, 2012.

[37] F. G. Leng, Y. X. Zhou, and J. Wang, Inspection and assessment of concrete durability, Building Materials Press, Beijing, China, 2012. 


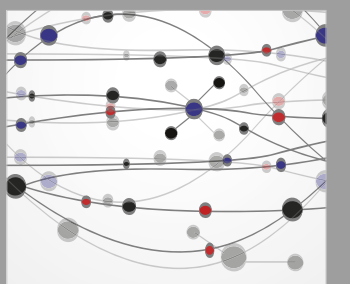

The Scientific World Journal
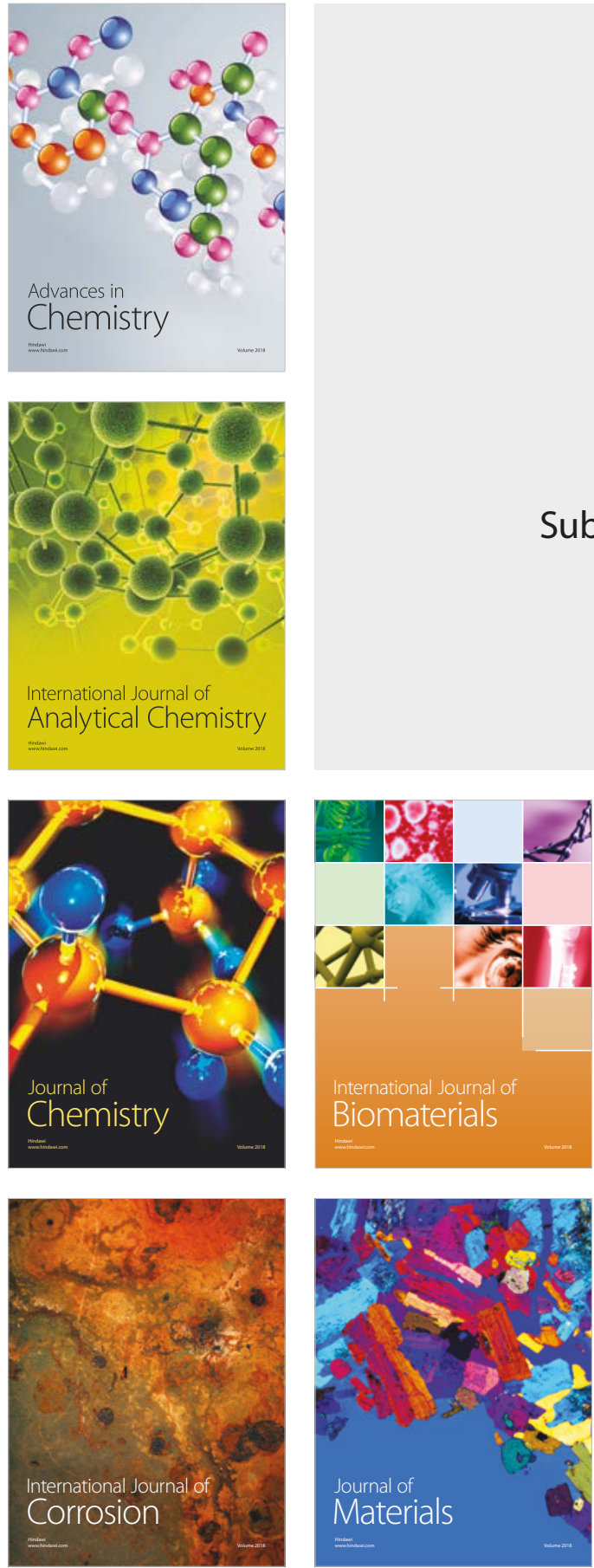

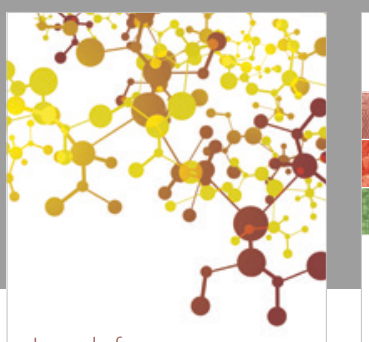

Journal of

Applied Chemistry
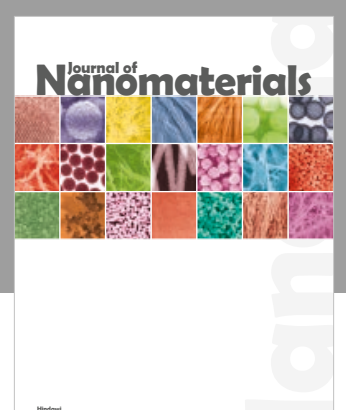

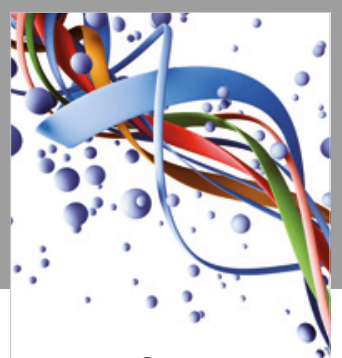

Scientifica

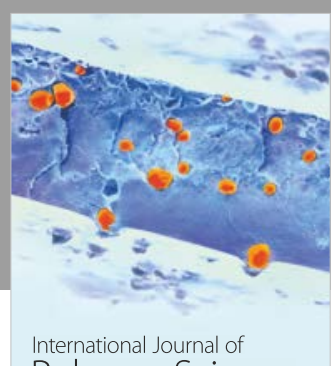

Polymer Science

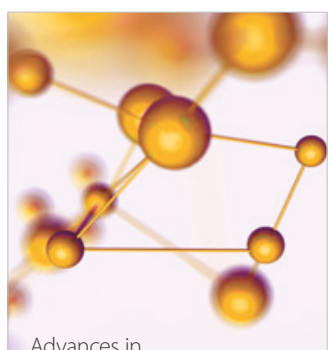

Physical Chemistry
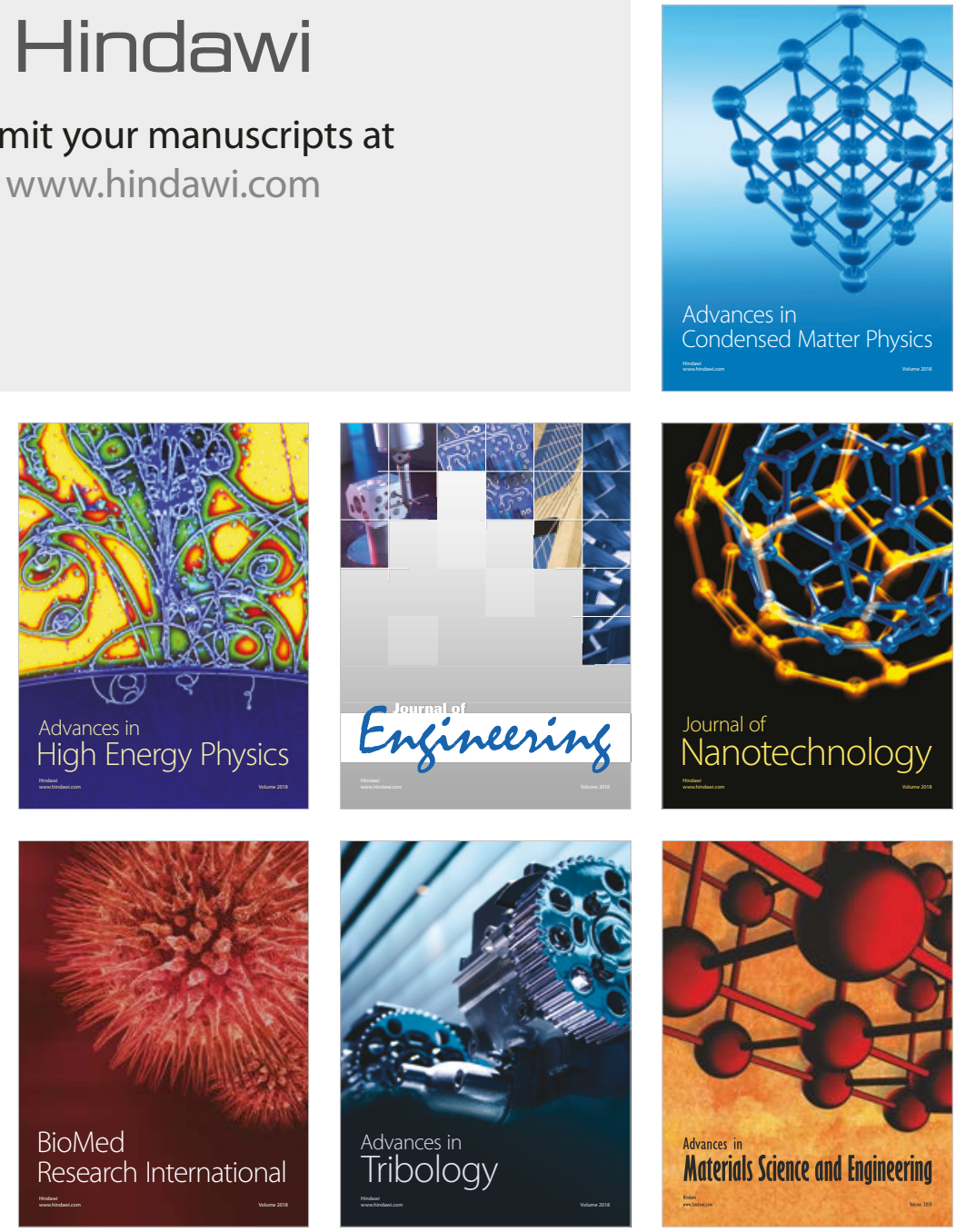